\section{A PRIMEIRA REPÚBLICA PORTUGUESA (1910-1926): PARTIDOS E SISTEMA POLÍTICO}

\section{Manuel Baiôa}

CIDEHUS - Universidade de Évora manuelbaioa@hotmail.com

Citation/Cómo citar este artículo: Baiôa, M. (2014). "A Primeira República Portuguesa (1910-1926): partidos e sistema político". Arbor, 190 (766): a114. doi: http://dx.doi. org/10.3989/arbor.2014.766n2006

Recibido: 13 febrero 2014. Aceptado: 31 marzo 2014.

La Primera República Portuguesa (1910-1926): partidos y sistema político

RESUMEN: El Partido Republicano Portugués se convirtió en el partido dominante del sistema político de la Primera República Portuguesa (1910-1926) debido a causas históricas, organizacionales, clientelistas, violentas y constitucionales. La oposición sentía que difícilmente conseguiría la alternancia política a través de elecciones, y por lo tanto, recurre a prácticas violentas e inconstitucionales para llegar al gobierno. Los partidos políticos portugueses se modernizaron en este período, pero no se convirtieron en partidos de masas. En las principales ciudades actuaban como partidos de cuadros y en las zonas rurales como partidos de notables. Durante la Primera República no se dieron pasos consistentes para democratizar el sistema político. Portugal se mantuvo ancorado a la tradición liberal y elitista del siglo XIX, aunque en una versión republicana.

PALABRAS CLAVE: Portugal; Primera República Portuguesa; Partido Republicano Portugués; partido de notables; partido de cuadros; partido de masas.

\section{PORTUGUESE FIRST REPUBLIC (1910-1926): POLITICAL PARTIES AND POLITICAL-SYSTEM}

Copyright: (c) 2014 CSIC. Este es un artículo de acceso abierto distribuido bajo los términos de la licencia Creative Commons Attribution-Non Commercial (by-nc) Spain 3.0.

ABSTRACT: For historical, organisational, clientelist, violent and constitutional reasons the Portuguese Republican Party became the dominant party in the political system of the Portuguese First Republic (1910-1926). The opposition felt alternation via elections would be difficult to achieve so resorted to violent and unconstitutional practices to reach government. The Portuguese political parties modernised themselves in this period, but failed to turn into mass parties. In major cities they acted as a cadre party and in the rural area as a party of notables. The First Republic failed to take solid steps to democratise the political system were And Portugal remained tied to the liberal and elitist tradition of the nineteenth century, although in a republican version.

KEYWORDS: Portugal; Portuguese First Republic; Portuguese Republican Party; party of notables; cadre party; mass party. 


\section{O PARTIDO REPUBLICANO PORTUGUÊS: PARTI- DO DOMINANTE DA I REPÚBLICA PORTUGUESA (1910-1926)}

O Partido Republicano Português (PRP), também conhecido por Partido Democrático, liderou a Revolução Republicana de 1910 e tornou-se no partido dominante (quase hegemónico) do sistema multipartidário da I República Portuguesa (Sousa, 1983; Lopes 1990). No entanto, não era um partido coeso, uma vez que federava muitos interesses e individualidades heterogéneas (Queirós, 2008). A preponderância do PRP durante a I República e a ausência de alternância provocaram uma identificação entre o partido e o regime, dado o controlo do aparelho do Estado por parte do PRP e a dificuldade das forças da oposição em aceder aos órgãos do poder. Esta situação provocou uma crise de representatividade e de participação política e reforçou a deslegitimação e a instabilidade da República (Lopes, 1994; Leal, 2009). Foi a partir deste partido abrangente que surgiram através de várias dissidências praticamente todos os outros partidos relevantes da I República. Apenas à direita o Partido Monárquico, o Centro Católico Português e a União dos Interesses Económicos e à esquerda o Partido Socialista e o Partido Comunista Português tiveram uma origem diferente. Este facto marcou o regime republicano dado o desejo inquebrável dos dirigentes do PRP de liderarem um movimento frentista no governo e no Parlamento que reunisse toda a família republicana desavinda.

O domínio do sistema político pelo PRP tem sido explicado por razões "históricas", "organizativas", "clientelares", "violentas" e "constitucionais". O facto de ter sido este partido que desde o período da propaganda republicana, no período monárquico, difundiu a ideologia republicana e preparou a revolução de 5 de Outubro de 1910 deixou marcas profundas no povo e nas elites republicanas. Esta base social de apoio inicial, associada à integração de alguns dirigentes dos antigos partidos monárquicos, permitiu-lhe criar uma densa rede organizativa e de influência por todo o país, quando comparada com a débil estrutura dos seus dois primeiros rivais, o Partido Republicano Evolucionista (19121919) e a União Republicana (1912-1919). Os líderes políticos destes dois partidos republicanos moderados, António José de Almeida e Brito Camacho, abandonaram o Partido Republicano Português com os seus amigos em finais de 1911, mas tiveram de deixar atrás de si o nome oficial do partido que tinha conseguido implantar a República em Portugal e a máquina partidária que incluía comissões políticas, jornais e centros associativo-políticos em quase todas as cidades e vilas portuguesas. O Partido Republicano Português tinha assim, o caminho aberto para se apoderar progressivamente dos recursos do Estado: Afonso Costa presidiu ao primeiro governo monopartidário da República a partir de 9 de Janeiro de 1913; nas eleições suplementares de Novembro de 1913 o PRP obteve a maioria absoluta no Congresso; em Janeiro de 1914 tomaram posse as primeiras vereações das Câmaras Municipais resultantes de eleições, que reforçaram o domínio do PRP na província. O domínio do poder central e do poder local reforçou o caciquismo exercido pelo PRP, uma vez que passou a dispor de maiores recursos públicos para disponibilizar aos seus clientes.

A lei eleitoral também foi usada em função dos interesses do Partido Republicano Português. Os republicanos tinham sempre defendido a adoção do sufrágio universal masculino durante a Monarquia. Em 1911 aprovaram uma lei que alargou o sufrágio a todos os cidadãos maiores de 21 anos que soubessem ler e escrever, ou que fossem chefes de família, com algumas exceções. Esta lei permitia que $14,2 \%$ da população portuguesa participasse no ato eleitoral. Era um passo em frente na aproximação ao sufrágio universal masculino. No entanto, após a formação de novos partidos republicanos e do perigo dos partidos monárquicos participarem nas eleições, o PRP fez aprovar uma nova lei eleitoral em 1913 que limitava a capacidade eleitoral apenas aos cidadãos masculinos maiores de 21 anos que soubessem ler e escrever, pelo que apenas 7,7\% da população pode participar nas eleições desse ano, uma vez que o analfabetismo atingia $69 \%$ da população portuguesa. Esta lei eleitoral reforçou o tipo de clientelismo que o PRP podia oferecer - o acesso aos serviços e ao aparelho do Estado. Esta lei afastou do sufrágio as massas analfabetas do campo, fáceis de convencer pelos caciques católicos, monárquicos e conservadores, diluiu o clientelismo tradicional específico das sociedades fortemente ruralizadas e reforçou o clientelismo de transição, mais urbano e administrativo. O cacique proprietário passou a competir com novos patronos e intermediários (comerciantes, médicos, advogados e funcionários públicos), afetos maioritariamente ao partido do governo, que controlavam e proporcionavam certos recursos, bens e serviços. O clientelismo tradicional perdeu assim importância em relação ao clientelismo estatal, administrativo, autárquico e profissional que estava nas mãos do PRP. O sistema de sufrágio capacitário restrito aos homens alfabetizados manteve-se durante toda a I República, com exceção da presidência de Sidónio Pais, em 1918, onde pela primeira vez e de forma efémera, se instituiu o sufrágio universal masculino, 
alargando-se o sufrágio a todos os homens maiores de 21 anos (Marques, 1991; Lopes, 1994, 2013; Silva, 1997; Almeida, 1998; Baiôa, 2000; 2012).

Este domínio histórico, organizativo e clientelar do PRP também foi reforçado pelas práticas violentas exercidas pelos membros do PRP contra os seus adversários. A tradição revolucionária, jacobina e violenta que o partido trouxe da Monarquia prolongou-se no regime republicano, desta vez já não só contra os monárquicos, mas também contra os seus antigos irmãos republicanos. Agredir um líder do Partido Republicano Evolucionista, incendiar ou destruir a sede de um partido ou jornal monárquico ou católico tornouse uma prática corrente que as autoridades policiais e judiciais deixavam passar impunemente (Valente, 1982; Valente, 1997; Ramos, 2001; Ramos 2004).

Por último, o regime constitucional criado pela República também facilitou a preeminência do PRP. A constituição de 1911 criou um regime político onde a supremacia parlamentar era clara. O Congresso, dividido na Câmara dos Deputados e no Senado, era eleito por sufrágio direto e competia-lhe legislar e fiscalizar a ação do governo e da administração pública e eleger o Presidente da República para um período de quatro anos, não prorrogável no mandato seguinte. Ao chefe de Estado cabia-Ihe nomear o governo e promulgar as leis. No entanto, não possuía veto absoluto ou suspensivo sobre as leis, não podia dissolver o Parlamento ou prorrogar o seu funcionamento, mas podia ser destituído por deliberação de dois terços dos membros do Congresso, o que enfraquecia bastante a sua magistratura. Com a revisão constitucional de 1919 o Presidente da República passou a poder dissolver o Congresso, mas mediante prévia consulta do Conselho Parlamentar (Miranda, 1985; Matos, 2010; AA. VV., 2011; Araujo; Chorão, 2011).

Em conclusão, o Partido Republicano Português ao liderar a Revolução de 5 de Outubro de 1910, ao conseguir obter uma maioria clara no Congresso em 1911 e principalmente em 1913, reforçou a sua hegemonia no sistema político e as forças da oposição teriam de futuro, muitas dificuldades em aceder aos órgãos de poder cumprindo a constituição, uma vez que as eleições estavam viciadas e não havia nenhum mecanismo constitucional que forçasse a alternância política.

\section{A OPOSIÇÃO AO PARTIDO REPUBLICANO PORTUGUÊS}

Este domínio incontestável do PRP converteu-se numa autêntica "ditadura" para a oposição. Esta sentia que dificilmente conseguiria a alternância por via eleitoral sem recorrer a práticas anticonstitucionais ou violentas.

O início da I Guerra Mundial e a decisão do Partido Republicano Português de participar ao lado dos aliados veio reforçar a intervenção dos militares na política e ampliou as tensões dentro da sociedade e dos partidos portugueses. O Presidente da República, Manuel de Arriaga, sensível aos argumentos dos republicanos conservadores nomeou em 25 de Janeiro de 1915 um executivo de iniciativa presidencial, liderado pelo general Pimenta de Castro, constituído maioritariamente por militares, sem o apoio do Congresso. $\mathrm{O}$ PRP considerou esta decisão anticonstitucional, pelo que se estaria a viver em "ditadura", e por isso, agiu de forma violenta a 14 de Maio do mesmo ano. O regresso do PRP ao poder não desarmou a oposição na sua estratégia e Machado Santos, o herói da implantação da República, tentou um golpe de Estado a 13 de Dezembro de 1916 e Sidónio Pais a 5 de Dezembro de 1917. Se o primeiro caiu frustrado, o segundo frutificou num regime republicano alternativo, que conseguiu num primeiro momento agrupar todas as fações contrárias à política empreendida desde 1910 pelo Partido Republicano Português.

O regime liderado por Sidónio Pais, conhecido por "Sidonismo" ou "Nova República" (Dezembro de 1917 a Dezembro de 1918), antecipou algumas soluções políticas empreendidas pelas ditaduras europeias autoritárias e fascistas dos anos vinte e trinta. Com Sidónio Pais houve uma recuperação dos valores tradicionais e ordeiros, num sistema político carismático, presidencialista e populista. O Estado ganhou um papel mais interventivo contra a plutocracia e repressivo contra o movimento operário e republicano de esquerda. Por outro lado, Sidónio Pais procurou avançar para uma nova organização política e ultrapassar o divisionismo criado pelo Liberalismo e pelo Republicanismo, aproximando-se dos católicos, dos monárquicos e de outros corpos sociais banidos dos órgãos do poder desde 1910. Avançou-se para uma superação dos partidos políticos e do Parlamento enquanto forma de representação dos interesses nacionais com a criação dos organismos corporativos, com a formação de um esboço de partido único agregador das tendências conservadoras (Partido Nacional Republicano) e com o novo papel mobilizador do "chefe" (Telo, 2000; Meneses, 1998; Silva, 2006).

A corrente central de opinião que defendia o presidencialismo autoritário republicano contrário ao parlamentarismo chegou ao governo apenas com Si- 
dónio Pais, mas tinha já dado mostras da sua presença desde o tempo da propaganda republicana durante a Monarquia. O forte impacto que a participação de Portugal na Grande Guerra provocou na sociedade portuguesa permitiu uma aliança tática de vários sectores contrários à política do PRP. Inicialmente Sidónio Pais teve o apoio do seu partido (União Republicana), do Partido Centrista Republicano (dissidência do Partido Republicano Evolucionista), e de sectores aparentemente divergentes: monárquicos, católicos e operariado (Telo, 1977; Cruz, 1980; Samara, 2002; Santos, 2003). Este bloco desfez-se quando Sidónio Pais avançou para a criação dum regime presidencialista. A criação no início de Abril do partido de apoio ao regime - Partido Nacional Republicano, no qual se fundiu o Partido Centrista Republicano, e a eleição simultânea do Presidente da República e do Congresso em 28 de Abril de 1918, provocou o abandono do governo dos três membros da União Republicana e o início de uma política de distanciamento face ao regime. Sidónio Pais foi eleito Presidente da República, sem oposição, e o partido do regime obteve a maioria absoluta na Câmara dos Deputados (108 deputados em 155) com o suporte da censura, sem a participação dos principais partidos republicanos, mas com sufrágio universal masculino. Os monárquicos que participaram pela primeira vez nas eleições após a proclamação da República elegeram 37 deputados e os católicos e os independentes 5. Continuou a haver um partido dominante no Congresso, desta vez de cariz conservador, mas as tensões e as divergências à esquerda e à direita intensificaram-se, uma vez que o Sidonismo não atendeu a todas as suas reivindicações. O Congresso e o Partido Nacional Republicano tiveram uma ação irrelevante e pouco mobilizadora dentro do regime. Ficaram submetidos à ação do Presidente, o que realçou as divergências internas (Samara, 2004; Meneses, 2011).

O vazio de poder criado com o assassinato de Sidónio Pais a 14 de Dezembro de 1918 conduziu o país a uma guerra civil. No norte de Portugal foi proclamada a Monarquia em 19 de Janeiro de 1919 e passados quatro dias rebentou em Lisboa uma insurreição monárquica. O perigo monárquico desfez o que restava do bloco "Sidonista" e uniu temporariamente os republicanos desavindos na defesa das suas instituições. Em poucas semanas a revolta monárquica foi debelada.

Após o Sidonismo parecia que se tinha regressado à situação política da primeira fase da República. A elite sidonista agrupada em torno do Partido Nacionalista Republicano entrou em abatimento e dividiu-se. Um grupo formou o Partido Republicano Conservador com o objetivo de criar um sistema bipartidário rotativista, mas viria a desintegrar-se em 1920. Um outro grupo fundou o Partido Nacional Republicano Presidencialista, com o objetivo de continuar herança do Sidonismo, realçando o corporativismo e a dimensão antiliberal. No entanto, teve uma importância residual no sistema de partidos da I República, embora os seus membros viessem a integrar um leque variado de organizações conservadoras. Uma parte da sua elite ingressou no Partido Republicano Liberal em 1919, outra parte integraria em 1925 o sector conservador republicano, encarnado então pelo Partido Republicano Nacionalista e outra parte esteve no início da formação dos grupos radicais nacionalistas próximos do fascismo. O irreverente Machado Santos continuou a não querer integrar os partidos tradicionais, tendo fundado em 1919 a Federação Nacional Republicana. Nos partidos republicanos tradicionais parecia que nada tinha mudado. O Partido Republicano Português conseguiu nova maioria absoluta no Parlamento nas eleições de 11 de Maio de 1919 ao eleger 86 deputados dos 163 que compunham a Câmara dos Deputados. Os partidos republicanos conservadores anularam-se parcialmente na maior parte dos círculos eleitorais, o que contribuiu para que obtivessem resultados modestos, embora superiores em relação às eleições de 1915. O Partido Republicano Evolucionista elegeu 38 deputados e a União Republicana 17, o que os colocava como as principais forças da oposição, mas sem possibilidade de representarem uma alternativa no Parlamento à supremacia do PRP. Os independentes e os socialistas viram a sua influência crescer significativamente nestas eleições do pósguerra, tendo os primeiros elegido 13 deputados e os segundos 8 . Os católicos voltaram a conseguir eleger 1 deputado, mas baixaram a sua representação parlamentar face ao Sidonismo e os monárquicos voltaram a não ter condições políticas para se apresentarem às urnas, dada a proximidade da insurreição monárquica e a posterior violência e coação republicana (Baiôa, 2004; Leal, 2008).

No entanto, a situação política estava profundamente alterada depois da participação de Portugal na I Guerra Mundial e das experiências "autoritárias" de Pimenta de Castro e de Sidónio Pais. Os partidos republicanos e os políticos estavam profundamente divididos entre intervencionistas e neutralistas, entre apoiantes de Pimenta de Castro e participantes na revolução de 14 de Maio de 1915 e entre Sidonistas e "verdadeiros republicanos". Estes ressentimentos agravados por ódios pessoais afetaram internamente 
todos os partidos (Meneses, 2004). Afonso Costa, o líder carismático do PRP e da primeira fase da I República (1910-1917), afastou-se do país e do seu partido profundamente magoado pelas incompreensões de que tinha sido vítima. O preço que colocou para o seu regresso ao governo era impraticável - a união de todos os partidos republicanos. Nem dentro do PRP isso foi possível. Foi difícil encontrar uma estratégia e um líder consensual dentro do PRP após 1919. A orgânica interna dos partidos republicanos assentes em Diretórios e contrários ao presidencialismo também contribuiu para acentuar os conflitos internos e as cisões. Os novos candidatos a líderes do PRP, António Maria da Silva, Domingos Pereira e Álvaro de Castro, enfrentaram as suas estratégias e o seu pessoal político no partido e no Parlamento, chegando ao ponto de governos do PRP caírem com votos de deputados do PRP, casos do governo de Sá Cardoso, a 21 de Janeiro de 1920 e Domingos Pereira a 4 de Março de 1920. Em Março/Abril de 1920 Álvaro de Castro, conjuntamente com 19 deputados e 10 senadores abandonou o PRP. Nos meses seguintes, outros parlamentares viriam a unir-se ao grupo de Álvaro de Castro formando o Partido Republicano de Reconstituição Nacional que chegou a contar com 33 deputados e 10 senadores (Silva, 1996). Em Novembro de 1920 Domingos Pereira, conjuntamente com os seus amigos, também criou uma nova dissidência dentro do PRP, mas viria a integrar-se novamente no seu antigo partido em Dezembro de 1921. O Partido Republicano Português deixou de ter a maioria absoluta na Câmara dos Deputados desde Março de 1920 e só voltou a recuperá-la em Dezembro de 1925. Esta situação deveu-se à falta sistemática de alguns parlamentares às sessões do Parlamento, mas principalmente às cisões e à falta de coesão do PRP (Marques, 1980; Farinha, 2002; Baiôa, 2012).

A fragmentação não afetava apenas o PRP. O Partido Republicano Evolucionista, a União Republicana e o Partido Monárquico também viviam momentos de instabilidade interna. Os fracos resultados eleitorais obtidos pelos dois partidos republicanos conservadores em Maio de 1919 levaram-nos a reconhecer o erro cometido no mês anterior, ao recusarem a fusão num partido das direitas republicanas, alternativo ao PRP. Esta fusão viria a concretizar-se em Outubro de 1919, com o aparecimento do Partido Republicano Liberal. Os líderes históricos dos dois antigos partidos republicanos, António José de Almeida e Brito Camacho, estavam a retirar-se progressivamente da política partidária, tendo o primeiro sido eleito Presidente da República em Agosto de 1919 e o segundo desempenhou o cargo de Alto-comissário de Moçambique entre 1920 e 1923. O novo Chefe de Estado, António José de Almeida, viu o seu poder reforçado devido à revisão constitucional de 1919 , que proporcionava ao Presidente da República o poder de dissolver o Congresso, após parecer do conselho parlamentar. Esta alteração constitucional dava ao partido que dominasse o executivo a oportunidade de manobrar as eleições em seu favor, o que previsivelmente quebraria a invencibilidade do PRP. No entanto, a vida do Partido Republicano Liberal não foi fácil, dividido internamente pela contínua ligação dos seus membros às antigas fidelidades partidárias e pelo facto de alguns parlamentares insatisfeitos com a fusão terem enveredado pela formação do Partido Popular, que adotou uma orientação esquerdista, o que Ihe valeu o ingresso de políticos de diferentes partidos, em particular de antigos membros do PRP.

Esta fragmentação alterou ligeiramente o sistema de partidos. De 1910 a 1917 tínhamos um multipartidarismo circunscrito de partido dominante. De 1920 a 1925, passamos a ter um multipartidarismo disperso de partido dominante, com uma pulverização crescente das forças partidárias. O PRP continuou a ter um papel predominante, embora desta vez mais fragilizado. Após as eleições de 1925 o PRP reforçou novamente a posição de partido dominante do sistema partidário (Sousa, 1983; Baiôa, 2012).

A violência política e social agravou-se no início dos anos vinte, fruto da deterioração das condições de vida no contexto do pós-guerra. A incapacidade dos governos para resolver os problemas financeiros e da ordem pública, associada à maior visibilidade dos militares após a I Guerra Mundial, sujeitou o poder civil ao poder militar. Os membros das forças armadas passaram a desempenhar um papel mais relevante dentro dos partidos, do Parlamento e nos governos, facto sem paralelo na Europa de então. E, à semelhança do que sucedeu em Espanha, também formaram "juntas militares" em 1918 e 1919. No entanto, esta maior participação dos militares nas instituições políticas da I República não permitiu resolver os problemas corporativos e financeiros que afetavam o enorme número de oficiais portugueses do pós-guerra. Uma parte dos militares deixou de se identificar com o regime e com o PRP e preparou inúmeras sublevações (Carrilho, 1985; Ferreira, 1992).

A pulverização e indisciplina partidária associada ao problema da ordem pública e à interferência dos militares nas instituições políticas provocaram uma instabilidade governativa galopante. O Presidente da República nomeou entre 15 de Janeiro de 1920 e 2 
de Março de 1921 dez governos com várias combinações partidárias. O Congresso eleito em 1919 estava muito transformado devido às dissidências, às fusões e à desordem dentro dos partidos. Os pequenos partidos, como o Partido Republicano de Reconstituição Nacional e o Partido Popular, passaram a desempenhar um papel decisivo na formação dos executivos através de entendimentos parlamentares com os grandes partidos (PRP e Partido Republicano Liberal). Era evidente que já não era possível encontrar uma solução governativa estável com aquele Parlamento. Esta era a oportunidade que há muito anos esperavam os republicanos conservadores. O Presidente da República, António José de Almeida, pôde, devido à revisão constitucional de 1919, nomear um governo do Partido Republicano Liberal e dissolveu o Congresso. As novas eleições realizadas em 10 de Julho de 1921 deram, como era habitual, a vitória ao partido que estava no governo, embora não tivesse conseguido alcançar a maioria absoluta. O Partido Republicano Liberal elegeu 79 deputados (em 163), o Partido Republicano Português 54 e o Partido Republicano de Reconstituição Nacional 12. Os restantes 18 lugares da Câmara dos Deputados foram distribuídos por pequenas formações que poderiam desempenhar um papel importante dada a maioria clara, mas não absoluta, que o Partido Republicano Liberal conseguiu. Os monárquicos que finalmente tiveram condições para ir às urnas obtiveram 4 deputados, os independentes 5, Católicos 3, Dissidentes 3, Regionalistas 2 e Populares 1 (Marques, 1980; Baiôa, 2004).

A vigência do novo governo do Partido Republicano Liberal liderado por António Granjo seria, no entanto, breve e viria a terminar tragicamente. As consequências económicas e sociais do pós-guerra acentuaramse no Verão de 1921 e o governo viu-se obrigado a tomar algumas medidas impopulares que estimularam uma insurreição esquerdista. A 19 de Outubro de 1921 rebentou um pronunciamento militar contra o governo. Este, ao verificar a impossibilidade de resistir demitiu-se. Porém, uma corrente radical acabou por sequestrar e matar o presidente do governo demissionário, António Granjo, conjuntamente com outras figuras importantes do regime republicano. Este acontecimento violento, conhecido por "noite sangrenta", marcou fortemente as elites e a opinião pública portuguesa. Ficou demonstrada a fragilidade das instituições republicanas e provou-se que a República era apenas um regime democrático na aparência, dado que nem admitia a alternância de partidos no poder, habitual nos regimes elitistas do século XIX.
A "noite sangrenta" acentuou o descrédito e a deslegitimação dos partidos políticos, da classe dirigente portuguesa e da própria República. No entanto, foi um tónico para que os políticos republicanos tomassem consciência que era necessário fazer uma trégua. Foi finalmente possível governar com alguma estabilidade. Um pacto concertado entre os principais partidos republicanos permitiu formar um governo de concentração integrando membros do Partido Republicano Português, do Partido Republicano Liberal, do Partido Republicano de Reconstituição Nacional e independentes, chefiado por Cunha Leal, que preparou as novas eleições legislativas de 29 de Janeiro de 1922. O Partido Republicano Português voltou a ganhar as eleições, mas sem maioria absoluta (71 deputados em 163). O Partido Republicano Liberal foi a segunda força mais votada, obtendo 33 deputados, seguido do Partido Republicano de Reconstituição Nacional com 17 e dos Governamentais de Cunha Leal com 13. Os partidos republicanos minoritários contavam com o desprestígio do PRP e a divisão interna do Partido Republicano Liberal para integrarem governos de concentração republicana. No entanto, o Partido Republicano Português através de uma aproximação aos católicos (5 deputados), aos regionalistas ( 2 deputados) e do apoio de alguns independentes (5 deputados), que o próprio PRP tinha ajudado nalguns casos a eleger, conseguiu uma maioria suficiente no Parlamento para formar um governo liderado por António Maria da Silva (Silva, 1996; Baiôa, 2004; Farinha, 2009).

A nova inclinação conciliadora e conservadora do PRP e o apaziguamento com a Igreja Católica após a "noite sangrenta" conduziu a que alguns radicais esquerdistas saíssem do PRP, para se associarem a alguns membros do Partido Popular, formando o Partido Republicano Radical. Esta depuração à esquerda do PRP não ficou totalmente resolvida, dado que continuaram as divergências internas, ideológicas e pessoais, entre "ordeiros" (linha conservadora encabeçada por António Maria da Silva) e "canhotos" (linha esquerdista liderada por José Domingues dos Santos). Este conflito latente culminou em Julho de 1925, quando um grupo de parlamentares canhotos se juntou à oposição para derrubarem um governo ordeiro do PRP liderado por António Maria da Silva. Os parlamentares canhotos foram irradiados do partido e formaram o Partido Republicano da Esquerda Democrática. O PRP embora continuasse a ganhar as eleições estava a ficar isolado e cercado. Os conservadores não confiavam nele devido à herança jacobina e os radicais tinham-no abandonado devido ao seu aburguesamento e à sua crescente concórdia com o bloco da direita (Ramos, 2001; Queirós, 2008; Rosas, 2010). 
Do lado conservador as divergências também permaneciam. Contudo, a perspetiva de um conflito interno no PRP incentivou um maior esforço de unidade. Depois de alguns meses de negociações formou-se, em Fevereiro de 1923, o Partido Republicano Nacionalista que reunia o Partido Republicano de Reconstituição Nacional e o Partido Republicano Liberal, ao qual já se tinha associado recentemente Cunha Leal e os seus apaniguados. Este novo partido republicano conservador tinha fortes aspirações de vir a tornar-se uma alternativa de direita ao PRP dentro de uma Republica que eles pretendiam "para todos os portugueses". Iniciou rapidamente uma campanha de obstrucionismo junto do Congresso ao governo do PRP de António Maria da Silva, chegando a abandonar o Parlamento entre 2 de Maio e 22 Junho de 1923 e entre 18 de Fevereiro e 22 de Abril de 1925. Os membros do Partido Republicano Nacionalista procuraram ainda influenciar o Presidente da República para dissolver o Congresso e para os nomearem para o executivo, podendo assim, conduzir à sua maneira as eleições. Mas, o Presidente da República, Manuel Teixeira Gomes, optou por tentar formar um "governo nacional" presidido por Afonso Costa, que deveria ter a colaboração e a participação do Partido Republicano Nacionalista. Todavia, este partido recusou formar governo com o Partido Republicano Português, pelo que Afonso Costa exilou-se novamente em Paris. As divergências internas no PRP ditaram a nomeação de um executivo minoritário do Partido Republicano Nacionalista liderado por António Ginestal Machado a 15 de Novembro de 1923. Porém, este governo viria a ser efémero devido à revolta militar de 10 de Dezembro de 1923, à recusa do Presidente da República em conceder a dissolução parlamentar e ao facto de ter um apoio minoritário no Congresso. A queda do governo do Partido Republicano Nacionalista agravou as divergências entre alguns dos seus membros, tendo um grupo liderado por Álvaro de Castro avançado para a cisão, formando o Grupo Parlamentar de Acção Republicana. Álvaro de Castro viria a ser chamado para chefiar o próximo executivo (18/12/1923), com o apoio maioritário do PRP. O Partido Republicano Nacionalista sofreu uma nova dissidência em Março de 1926 quando Cunha Leal e os seus amigos abandonaram o IV Congresso do seu antigo partido para formarem a União Liberal Republicana (Pinto, 1995; Farinha, 2009; Baiôa, 2012).

Entre 18 de Dezembro de 1923 e o final da I República, o PRP voltou a dominar os sete governos que se formaram. Contudo, foram maioritariamente governos de coligação, contando com o apoio do Grupo
Parlamentar de Acção Republicana e dos independentes. No entanto, a queda e formação destes governos derivaram frequentemente do litígio e da proeminência da tendência esquerdista ou ordeira do PRP.

Depois de várias tentativas falhadas de reforma do sistema político e de unificação das forças republicanas conservadoras, o Partido Republicano Português continuou à frente de uma República descredibilizada. A desconfiança no sistema eleitoral e nos partidos políticos levou a que vastos interesses económicos e sociais buscassem uma representação e uma atuação direta perante o poder, sem nenhum tipo de mediação política, dado que não se sentiam suficientemente representados e defendidos pelo Parlamento, pelos partidos e pelo governo.

O descrédito dos partidos enquanto organizações de mediação da sociedade com o poder político e a necessidade de criar um governo forte, fora dos partidos, também encontrou acolhimento entre as organizações patronais, o exército e as forças antiliberais. Estas organizações viraram-se sobre si mesmas numa estratégia "corporativa" de reforço orgânico, contra as instituições republicanas e contra a "ditadura do PRP". As elites económicas e sociais entraram em rota de colisão com os governos do PRP em 1924, após o aumento de alguns impostos. As organizações patronais decidiram formar um partido (União dos Interesses Económicos) com o objetivo de intervir ativamente na política, dado que não se identificavam com nenhum dos partidos políticos existentes e sentiam-se alarmados com a agitação social, com a situação económica do país, com o desenvolvimento do comunismo e com a passividade e ineficácia dos poderes políticos. A tensão corporativa entre o exército e os governos republicanos também cresceu neste período. Ainda que os militares estivessem profundamente divididos em termos políticos e partidários, verificou-se uma crescente unidade na intervenção dos militares na política através de pronunciamentos militares no sentido de resolver os problemas corporativos das forças armadas e de criar um governo extrapartidário que afastasse a oligarquia do PRP do poder. A extrema-direita dividida entre organizações monárquicas e republicanas também enveredou por uma estratégia de unidade antissistema contra a "ditadura do PRP" (Pinto, 2004).

Um grupo de intelectuais republicanos liberais associados em torno da revista Seara Nova apercebeu-se do perigo que corria a República pela progressão do ideário antiliberal em Portugal tanto por via da direita radical - Integralismo Lusitano, Cruzada Nacional D. Nuno Álvares Pereira e Fascismo (Leal, 1999; Pinto, 
2001), como por via da esquerda radical - Anarquismo e Comunismo (Freire, 1992; Pereira, 1999; Madeira, 2013) e investiram na crítica e na reforma das instituições republicanas no sentido de conciliar a herança liberal com o fortalecimento do executivo. O grupo da Seara Nova atacou a partidocracia e defendeu a formação de um governo nacional de "competências", com poderes extraordinários conferidos pelo Parlamento como uma solução transitória para reformar o sistema político e cimentar o liberalismo. Alguns destes intelectuais ainda entraram efemeramente no governo de Álvaro de Castro, mas acabariam por sair desiludidos por não terem conseguido alterar o sistema político (Reis, 2004).

Embora o Partido Republicano Português voltasse a ganhar por maioria absoluta as eleições legislativas de 8 de Novembro de 1925, utilizando a violência, a fraude e acordos ilícitos com vários caciques, encontravase profundamente isolado e cercado pelos partidos, sindicatos, associações patronais e militares. Estas organizações passaram a atuar de forma desleal e semilegal, pois não acreditavam no sistema eleitoral e político. Assim, à semelhança de outros países europeus do pós-guerra, não havia um consenso básico sobre o funcionamento dos órgãos políticos e a falta de legitimidade democrática do regime, impedia superar a crise de eficácia das instituições políticas republicanas (Linz; Stepan, 1978; Linz, 1991; Pinto, 2000).

O último governo da I República liderado por António Maria da Silva (17/12/1925 a 30/5/1926) viu todas as organizações políticas da oposição explorarem alguns escândalos económico-financeiros, conspirarem contra o governo do PRP e desenvolverem um profundo obstrucionismo no Parlamento, não permitindo a votação de algumas leis. Para isso, utilizaram vários estratagemas, como a saída das sessões para não haver quórum, agredir um deputado ou simplesmente fazer um discurso de várias horas. A preparação e execução do golpe militar de 28 de Maio de 1926 teve a participação de elementos de quase todos os partidos, da esquerda à direita. Todos queriam implantar uma ditadura transitória que acabaria com a hegemonia do PRP e permitiria lançar as bases de um novo regime. No entanto, era apenas este o elo de união das forças políticas e militares que realizaram o movimento revolucionário que acabou com a I República (Farinha, 1998; Ramos, 2000; Ramos, 2001; Afonso, 2001; Baiôa, 2012).

\section{TRANSIÇÃO FALHADA PARA DEMOCRACIA E PARA OS PARTIDOS DE MASSAS}

Durante a I República Portuguesa manteve-se um sistema multipartidário de partido dominante, mas com uma elevada instabilidade política. Portugal teve 45 governos e 29 tentativas de golpe de Estado entre 1910 e 1926 e apresentou o maior índice de instabilidade governativa da Europa no período anterior à grande depressão, com uma duração média de 117 dias por cada executivo (1918 a 1926). Em segundo lugar encontrava-se a Jugoslávia com uma duração média de 154 dias e em terceiro lugar a Espanha com uma duração média de 166 dias (Linz, 1991).

A instabilidade governativa derivou essencialmente de dois problemas. Em primeiro lugar, o Partido Republicano Português, embora dominasse o Parlamento, não conseguiu criar consensos internos que dessem estabilidade ao poder executivo. O PRP formou essencialmente governos de coligação, com o apoio de outros partidos e de deputados independentes, o que favoreceu a discórdia dentro do PRP e o aparecimento de fações. Durante largos períodos o Directório do PRP não controlou o seu grupo parlamentar. Por isso, muitos governos do PRP caíram com votos de parlamentares do PRP. Em segundo lugar, houve uma incapacidade de encontrar mecanismos pacíficos de alternância ou de governação estável. Durante a I República continuou a viver-se num regime de "eleições feitas e não justas" que proporcionavam a vitória sistemática do partido do governo através de vários mecanismos de "engenharia eleitoral" (Freire, 2011; Baiôa, 2012). Por isso, os partidos da oposição não tendo confiança no funcionamento do sistema eleitoral, recorreram à violência e às revoluções para chegar ao poder: "são as revoluções e não as eleições que asseguram a alternância política" (Costa, 2001, 69). Na Monarquia Constitucional o Rei podia demitir o governo, nomear um novo governo da oposição, dissolver o Parlamento e marcar novas eleições que davam normalmente a vitória ao partido do governo. Este mecanismo de alternância política permitiu esbater durante algum tempo as tensões políticas. Durante a I República o sistema constitucional limitou esta prática. Assim, muitos políticos enveredaram pelos golpes de Estado para chegar ao governo, uma vez que o sistema eleitoral e constitucional não Ihes abria essa possibilidade. A violência e a revolução tornaram-se fontes de legitimação da alternância política que posteriormente a "soberania do povo" validava.

As várias fórmulas governativas ensaiadas (governos partidários, de coligação, de fação e de iniciativa presidencial) não tiveram sucesso duradouro devido principalmente às lutas internas no partido dominante da I República. Portugal manteve uma instabilidade política endémica, embora tivesse aparentemente um 
sistema partidário capaz de criar condições de grande estabilidade política. Os partidos radicais de esquerda e direita eram minoritários (o Partido Comunista Português e os movimentos e partidos fascistas nunca conseguiram eleger um deputado ou senador) e o Partido Republicano Português dominava o Parlamento. A fragmentação partidária deu-se principalmente nos partidos do centro político e não derivou normalmente de grandes divergências ideológicas, mas de diferenças pessoais entre os líderes (Schwartzman, 1989; Matos, 2010).

Em Portugal o pós-guerra não trouxe reformas no sentido de alargar a cidadania e não se deram passos para introduzir o sistema proporcional, nem círculos mais coerentes, como em Itália em 1918-19. Manteve-se o sistema eleitoral maioritário de lista incompleta (se o círculo elegia três deputados, o eleitor só podia votar em dois nomes) que assegurava a representação dos principais partidos minoritários, mas dava vantagem ao partido dominante. Continuaram a persistir índices de abstenção elevados e os partidos políticos continuaram a negligenciar a integração social e política das massas.

O clientelismo na Primeira República seguiu o modelo existente na Europa do Sul e manteve algumas características do período da Monarquia (Lyttelton, 1973; Varela Ortega, 1977, 2001; Graziano, 1980; Cazorla Pérez, 1992; Gellner, 1986; Moreno Luzon, 1995, 1999, 2006; Robles Egea, 1996; Forner, 1997). Apenas ganhou um cunho mais urbano e administrativo. 0 clientelismo assentava ainda fundamentalmente no papel dos caciques e não tanto nos partidos políticos enquanto organizações. A representação dos interesses não era canalizada pela "organização partido", mas por um conjunto de notáveis que acautelavam as suas causas e os seus protegidos individualmente, criando inúmeras redes de favores cruzados, muitas vezes incompatíveis dentro do mesmo partido. A organização partidária modernizou-se pouco, continuando com a mesma estrutura personalista de carácter oligárquico e caciquil que afastava a maioria dos seus membros das decisões e mantinha a população afastada da política. Os atos eleitorais internos e externos continuaram pouco transparentes e não foi possível consolidarem-se novos partidos de integração social que renovassem os líderes políticos e os seus procedimentos. A luta pelo poder continuou a centrar-se no controlo do poder executivo, o que atrasou o processo democrático, dado que houve uma menor integração dos interesses sociais e da participação dos cidadãos, sendo a fraude administrativa dominante e a corrupção marginal nos processos eleitorais. Esta imagem de organização clientelar transparecia para a opinião pública por meio de uma imprensa cada vez mais ácida em relação à ineficácia dos partidos e do Parlamento que não conseguia aprovar o orçamento na maior parte dos anos. A modernização e a democratização não foram requeridas intensamente pela sociedade, nem foram sugeridas pelos partidos. Estes mostraram que não estavam preparados e motivados para agrupar, modelar, moderar e canalizar para o sistema político os interesses e as exigências políticas de todos os estratos sociais. A continuação das práticas clientelares dos partidos de notáveis, a pouca lisura nos atos eleitorais e a ineficácia dos órgãos de soberania acentuaram a crise de legitimidade das instituições políticas e empurraram para fora do sistema político vastos grupos da sociedade que desenvolveram petições maximalistas e atividades revolucionárias (Almeida, 1991, 2011, 2012; Lopes, 1994, 2004, 2011, 2013; Silva, 1997; Baiôa, 2012).

No início da década de vinte, os principais partidos da I República já não eram "puros partidos de notáveis", à semelhança do que sucedia no mesmo período na Grécia (Mavrogordatos, 1983) e em Espanha, uma vez que tinham iniciado uma modernização e adaptação aos novos tempos. Estes partidos ainda estavam distantes dos partidos de massas, mas eram naquele momento bastante mais evoluídos que os tradicionais partidos de notáveis do século XIX. Estas organizações políticas ainda eram dominadas pela elite parlamentar e pelos ex-ministros e pelas suas clientelas de notáveis regionais e caciques locais, quando na Europa Ocidental se afirmavam os partidos de massas (Bernstein, 1980; Orsini, Quagliariello, 1996; Luebbert, 1997).

Os principais dirigentes dos partidos republicanos pertenciam às elites urbanas. A nível profissional, distinguiam-se os funcionários públicos, com uma presença esmagadora. Dentro dos funcionários públicos destacavam-se os militares, altos funcionários da administração pública, magistrados e professores. Os juristas, em particular os advogados, e os médicos também tinham um peso importante. Os políticos ligados em exclusivo à atividade agrícola, comercial e industrial eram minoritários na cúpula dos principais partidos da I República. A classe dirigente dos partidos estruturais da I República tinha uma elevada formação académica, uma vez que mais de $80 \%$ tinha estudado em instituições de ensino superior. Destacavam-se essencialmente três qualificações: Direito, formação militar e medicina. Comparando com 
os partidos europeus da mesma época, e particularmente com os da Europa do Norte, a elite partidária portuguesa tinha uma formação académica mais elevada. Esta diferença torna-se ainda mais acentuada quando se compara os dirigentes dos partidos portugueses com os dirigentes dos partidos de massas em afirmação na Europa dos anos vinte. Outra diferença notória é o peso maior da qualificação militar na elite partidária portuguesa. Por outro lado, a ascensão dos políticos portugueses na hierarquia do partido era mais rápida e não era necessário uma experiencia na política local para chegar aos lugares de topo, como acontecia em muitos partidos europeus, pelo que era comum chegar-se à direção central de um partido antes dos 40 anos (Silva, 1996; Marques, 2000; Best, Cotta, 2000; Almeida, Pinto, Bermeo, 2003; Almeida, Fernandes, Santos, 2006; Queirós, 2008; Leal, 2008; Baiôa, 2012; Almeida, 2012).

A tomada de decisões nos partidos portugueses estava centralizada no diretório e no grupo parlamentar. As estruturas locais dos partidos estavam dominadas pelos caciques que tinham uma grande autonomia funcional, pelo que podiam realizar alianças com base em interesses estratégicos e familiares, desprezando as teorias ideológicas. Os partidos continuavam a ter um funcionamento interno deficiente e irregular. Eram normalmente confederações pouco coesas e flexíveis de comissões locais independentes, chefiadas por um cacique, com uma fraca conexão horizontal e vertical com as outras estruturas partidárias. $\mathrm{Na}$ maior parte das localidades a mobilização política existia apenas nos momentos eleitorais. A organização e a burocracia partidária eram muito débeis e resumiam-se muitas vezes apenas a relações pessoais, a comissões políticas com atividade limitada aos períodos eleitorais, a centros associativo-partidários nas cidades e a alguns jornais nacionais e regionais. O sistema de registo dos membros era ainda muito arcaico e organizava-se junto das estruturas locais, sem o controlo das estruturas nacionais. Os partidos portugueses tinham um aparato organizativo bastante simples, ainda sem um rol de funcionários típico dos partidos de massas. O financiamento deste tipo de partidos passava já pelo contributo individual de cada membro, embora cada um pagasse consoante o seu estatuto social e permanecessem muito dependentes de receitas extraordinárias provenientes da fortuna pessoal dos notáveis. Além disso, por norma, os partidos, eram fracamente doutrinados mas profundamente pragmáticos. Não ambicionavam mobilizar grandes massas populacionais, nem transmitir uma imagem e uma identidade coletiva forte e con- sistente. Os seus aderentes tinham uma disciplina e fidelidade ideológica exígua e a relação com os seus eleitores não era baseada em mecanismos de delegação mas de confiança. O seu objetivo central era ter acesso privilegiado aos recursos do Estado e aliciar o maior número de influentes regionais e locais, dado que este tipo de partidos era composto pelo somatório dos notáveis e das suas clientelas locais. Estes notáveis podiam proporcionar prestígio, capacidade técnica e capital ao partido. A coesão interna mantinha-se pela perspetiva de distribuição de favores coletivos (uma estrada ou uma escola para uma localidade) e individuais (recomendações para empregos ou resolução de problemas burocráticos com a administração pública) dos patronos aos seus "afilhados", em troca de apoio político durante o processo eleitoral. A indisciplina, a fragmentação e as cisões neste tipo de partido foram frequentes, devido principalmente a diferenças pessoais e lutas de liderança. Estas cisões provocavam uma associação de notáveis e seus amigos em torno dos novos líderes com ramificações por todo o país, dando lugar, por vezes, à formação de um novo partido (Lopes, 1994; Silva, 1996; Queirós, 2008; Leal, 2008; Baiôa, 2012).

O Partido Republicano Português e os outros partidos portugueses não se transformaram em partidos de massas. Continuou a haver nestes partidos um desajuste e afastamento progressivo entre as reivindicações urbanas mais democratizadas e participativas, e, por outro lado, a manutenção da estrutura elitista de um partido de notáveis, com uma conceção monopolista, hierárquica e fechada do poder. No entanto, convém salientar que esta realidade não era monolítica nem eterna. Quase todos os partidos portugueses iniciaram uma aproximação a um modelo de partido mais moderno e funcional, com destaque para o Partido Republicano Português, seguindo o modelo de outros antigos partidos de notáveis da Europa, como o Partido Radical francês, o Maurismo e a Lliga Regionalista da Catalunha, em Espanha. Contudo, continuaram a persistir em Portugal partidos com uma organização política mais arcaica, de base quase exclusivamente parlamentar, com uma débil ou inexistente rede organizativa a nível nacional, como o Grupo Parlamentar de Acção Republicana -1924-1925 (Silva, 1996; Baiôa, 2012).

Dado que alguns partidos de notáveis na década de vinte já não tinham as mesmas características dos partidos do século XIX, alguma historiografia espanhola remodelou o conceito de "partido de notáveis" de Max Weber e o conceito de "partido de quadros" 
de Maurice Duverger. Os partidos que não se modernizaram continuariam a ser designados por partidos de notáveis, enquanto os que iniciaram uma modernização seriam designados por partidos de quadros. Desta forma os partidos de quadros representavam uma fase de transição na evolução dos partidos. Tinham perdido algumas das características tradicionais dos partidos de notáveis, uma vez que passaram a ter uma estrutura burocrática e organizativa quase permanente, uma elite mais diversificada e preparada para a política de massas e uma maior mobilização e enquadramento dos aderentes, mas ainda não tinham as características dos partidos de massas. Utilizavam uma estratégia política mista em simultâneo, com uma prática política moderna mais acentuada nos meios urbanos e uma política clientelar nos meios rurais. Entre as práticas políticas modernas podemos destacar o percurso dos candidatos pelo círculo em campanha eleitoral, a confraternização com os votantes, o comício, a eleição dos candidatos no seio do partido, a elaboração de um programa e a obtenção de favores para toda a coletividade e já não só para alguns indivíduos da mesma comunidade. As práticas tradicionais continuaram a persistir, em particular nos meios rurais, como a compra do voto, a ação dos caciques, a violência, a coação sobre os trabalhadores por parte do seu patrão, a intervenção do governador civil e de outros membros da administração pública, a fraude e a manipulação final dos resultados eleitorais (Arranz Notario, 1995; Sierra, 1996; Peña Guerrero, 1998; Varela Ortega, 2001; Moreno Luzón, 2006).

Em Portugal os partidos tinham uma estrutura que os aproximava dos partidos de quadros nas cidades, particularmente em Lisboa. No entanto, nos meios rurais continuavam com uma estrutura e uma prática política que os aproximava dos partidos de notáveis. Em relação a outros países da Europa do Sul, verificou-se um atraso considerável na modernização dos partidos políticos portugueses. Os partidos de quadros espanhóis ainda que continuassem acomodados às práticas clientelares, deram sinais de seguir as correntes democráticas da Europa do pós-guerra, com um programa reformista gradual que contrabalançava as ameaças revolucionárias (Suárez Cortina, 1986; Varela Ortega, 2001; Moreno Luzón, 2004). Os partidos de quadros italianos tiveram muita dificuldade em adaptar-se ao alargamento do sufrágio e à representação proporcio- nal introduzida em 1919, o que permitiu um reforço da influência política dos modernos partidos de integração social, como o Socialista e o Popular (Ridolfi, 1992, 1999; Pombeni, 1994; Noiret, 1994, 1997 a, 1997 b; Orsini, Quagliariello, 1996; Tarchi, 2000; Lotti, 2002).

$\mathrm{O}$ atraso na modernização da economia e da sociedade portuguesa e o facto de o regime republicano ter um cariz revolucionário atrasou a metamorfose interna dos partidos portugueses no sentido que se estava a operar em alguns países europeus - cooperação com o lento processo de democratização - ainda que isso significasse, a médio prazo, a superação destes partidos de notáveis por parte dos partidos de massas. A transição para a democracia em Portugal não dependeu só da vontade das elites políticas nacionais e locais, mas principalmente da sociedade no seu todo. Embora este estudo não analise o contexto social e económico, é evidente que a sociedade portuguesa dos anos vinte não estava ainda preparada para conseguir dar estabilidade a um sistema de democracia representativa, nem a outro tipo de partidos, como os partidos de integração social de massas, como os socialistas, comunistas e fascistas. Os partidos portugueses inseridos em sociedades civis frágeis continuaram a basear-se nas elites, desprezando as massas. O sistema político e social português tinha algumas características que o aproximavam mais dos regimes políticos da Europa Oriental e da América do Sul do que da Europa Ocidental, com uma sociedade rural, uma industrialização tardia e uma economia arcaica, inserida num sistema político de tradição parlamentar mas de competição e pluralismo limitado e com um baixo nível de mobilização política que facilitou a transição para uma ditadura de características tradicionais, onde a mobilização fascista era desnecessária ou mesmo prejudicial para proteger os interesses das elites dominantes (Mouzelis, 1986; Dogan, 1987; Lopes, 1994; Silva, 1997; Ramos, 2001; Pinto, 2000; Lopes, 2004; Ramos, 2004; Baiôa, 2012).

Em conclusão, durante a Primeira República (19101926) não se deram passos consistentes para a democratização do sistema político. Portugal continuou amarrado à tradição liberal e elitista do século XIX, ainda que numa versão republicana e com um sistema multipartidário de partido dominante com uma crescente falta de legitimidade. 
AA.VV. (2011). A Assembleia Constituinte e a Constituição de 1911. Lisboa: Assembleia da República.

Afonso, Aniceto (2001). História de uma conspiração: Sinel de Cordes e o 28 de Maio. Lisboa: Editorial Notícias.

Almeida, Pedro Tavares de (1991). Eleições e Caciquismo no Portugal Oitocentista (1868-1890). Lisboa: Difer.

Almeida, Pedro Tavares de (Organização e introdução de). (1998). Legislação eleitoral portuguesa: 1820-1926. Lisboa: Imprensa Nacional - Casa da Moeda.

Almeida, Pedro Tavares de (2011). "O sistema eleitoral e as eleições em Portugal (1895-1910): Uma perspectiva comparada". in André Freire (Coor.), Eleições e Sistemas Eleitorais no Século XX Português, Lisboa: Edições Colibri, pp. 85-99.

Almeida, Pedro Tavares de (2012). "Eleições e recrutamento parlamentar em Portugal". In Pedro Tavares de Almeida; Javier Moreno Luzón (Coord.), Das Urnas ao Hemiciclo. Eleições e Parlamento em Portugal (1878-1926) e Espanha (1875-1923). Lisboa: Assembleia da República, pp. 17-46.

Almeida, Pedro Tavares de; Fernandes, Paulo Jorge; Santos, Marta Carvalho dos (2006). "Os Deputados da 1.a República Portuguesa: Inquérito Prosopográfico". Revista de História das Ideias, Volume 27, pp. 399-417.

Almeida, Pedro Tavares de; Pinto, António Costa; Bermeo, Nancy (Ed.). (2003). Who Governs Southern Europe? Regime Change and Ministerial Recruitment (1850-2000). London: Frank Cass.

Araújo, António de; Chorão, Luís Bigotte (2011). "Política e Direito nos Alvores da Primeira República". in Luciano Amaral (Org.), Outubro: A Revolução Republicana em Portugal (1910-1926), Lisboa: Edições 70, pp. 117-140.

Arranz Notario, Luis (1995). “Modelos de partido". Ayer, N.o 20, pp. 81-110.

Baiôa, Manuel (2000). Elites políticas em Évora da I República à Ditadura Militar (1925-1926). Lisboa: Edições Cosmos.

Baiôa, Manuel (2004). “Partidos e sistema partidário na crise do Liberalismo em Portugal e Espanha nos anos vinte". in Manuel Baiôa (Ed.), Elites e Poder. A Crise do Sistema Liberal em Portugal e Espanha (1918-1931). Lisboa: Edições Colibri/CIDEHUS.UE., pp. 15-48.
Baiôa, Manuel (2012). Elites e Organizações Políticas na I República Portuguesa: O caso do Partido Republicano Nacionalista (1923-1935). (Tese inédita de doutoramento em História Contemporânea). Universidade de Évora.

Bernstein, Serge (1980). Histoire du Parti Radical. La Recherche de L'Age D'Or (1919-1926). Paris: Presses de la Fondation National des Sciences Politiques.

Best, Heinrich; Cotta, Maurizio (Edited by). (2000). Parliamentary Representatives in Europe 1848-2000. Legislative Recruitment and Careers in Eleven European Countries. Oxford: Oxford University Press.

Carrilho, Maria (1985). Forças Armadas e Mudança Política em Portugal no século XX. Para uma explicação sociológica do papel dos militares. Lisboa: Imprensa Nacional - Casa da Moeda.

Cazorla Pérez, José (1992). “Del Clientelismo tradicional al clientelismo de partido: evolución y características". Working Papers. Institut de Ciènces Politiques i Socials, n.o 55.

Costa, Fernando Marques da (2001). "Bernardino Machado". in António Costa Pinto (Coordenador), Os Presidentes da República Portuguesa, Amadora, Círculo de Leitores, pp. 60-71.

Cruz, Manuel Braga da (1980). As origens da Democracia Cristã em Portugal e o Salazarismo. Lisboa: Ed. Presença.

Dogan, Mattei (1987). “Romania, 19191938". in Myron Weiner; Ergun Ozbudun, (Edited by), Competitive elections in developing countries. Durham: Duke U.P., pp. 369-389.

Farinha, Luís (1998). O Reviralho: Revoltas republicanas contra a Ditadura e o Estado Novo 1926-1940. Lisboa: Editorial Estampa.

Farinha, Luís (2002). Estudo sobre a acção política parlamentar de Francisco Pinto Cunha Leal como Deputado ao Congresso da República (1918-1926). Porto: Edições Afrontamento/Assembleia da República.

Farinha, Luís (2009). Cunha Leal, Deputado e Ministro da República. Um notável rebelde. Lisboa: Texto Editores.

Ferreira, José Medeiros (1992). O comportamento político dos militares. Forças armadas e regimes políticos em Portugal. Lisboa: Ed. Estampa.
Forner, Salvador (Coord.). (1997). Democracia, elecciones y modernización en Europa. Siglos XIX y XX. Madrid: Cátedra.

Freire, André (2011). “Eleições, sistemas eleitorais e democratização: o caso português em perspectiva histórica e comparativa". in André Freire (Coor.), Eleições e Sistemas Eleitorais no Século XX Português. Lisboa: Edições Colibri, pp. 25-81.

Freire, João (1992). Anarquistas e operários. Ideologia, ofício e práticas sociais: anarquismo e o operariado em Portugal 1900-1940. Porto, Afrontamento.

Gellner, Ernest et al. (1986). Patronos y Clientes. Barcelona: Jucar Univ.

Graziano, Luigi (1980). Clientelismo e sistema político. Il caso dell'Italia. Milano: Franco Angeli Editore.

Leal, Ernesto Castro (1999). Nação e Nacionalismo. A Cruzada D. Nuno Álvares Pereira e as Origens do Estado Novo, (1918-1938). Lisboa: Edições Cosmos.

Leal, Ernesto Castro (2008). Partidos e Programas. O campo partidário republicano português (1910-1926). Coimbra: Imprensa da Universidade de Coimbra.

Leal, Ernesto Castro (2009). “Parties and Political Identity: the Construction of the Party System of the Portuguese Republic (1910-1926)". e-Journal of Portuguese History, vol. 7, n. 1, pp. 37-44. http:// www.scielo.gpeari.mctes.pt/cgi-bin/ wxis.exe/iah/? IsisScript=iah/iah.xis\&bas e=article\%5Edlibrary\&format=iso.pft\&la $\mathrm{ng}=\mathrm{p} \&$ nextAction $=$ Ink\&indexSearch $=\mathrm{AU}$ \&exprSearch=LEAL,+ERNESTO+CASTRO

Linz, Juan J. (1991), "La crisis de las democracias". in Mercedes Cabrera, Santos Juliá, Pablo Martín Aceña (Comps.), Europa en crisis, 1919-1939. Madrid: Editorial Pablo Iglesias, pp. 231-280.

Linz, Juan J.; Stepan, Alfred, (Ed.). (1978). The Breakdown of Democratic Regimes. Baltimore: Johns Hopkins U.P.

Lopes, Fernando Farelo (1990). “Um regime parlamentarista de partido dominante". in António Reis (Direção de), Portugal Contemporâneo. Vol. III, Lisboa: Publicações Alfa, pp. 85-100.

Lopes, Fernando Farelo (1994). Poder Político e Caciquismo na 1. ํ. República Portuguesa. Lisboa: Editorial Estampa.

Lopes, Fernando Farelo (2004). Os Partidos Políticos. Modelos e Realidades na Eu- 
ropa Ocidental e em Portugal. Oeiras: Celta Editora.

Lopes, Fernando Farelo (2011). "Direito de voto, regime de escrutínio e "eleições feitas" na I República Portuguesa". in André Freire (Coor.), Eleições e Sistemas Eleitorais no Século XX Português, Lisboa, Edições Colibri, pp. 101-123.

Lopes, Fernando Farelo (2013). "Caciquismo". in Maria Fernanda Rollo (Coordenadora Geral), Dicionário de História da I República e do Republicanismo. Volume I, Lisboa: Assembleia da República, pp. 483-487.

Lotti, Luigi (2002). “I Partiti dal sistema uninominal alla proporzionale: la classe dirigente liberale di fronte all' affermazione dei movimenti di massa". in Fernando Garcia Sanz (Ed.), España e Italia en la Europa Contemporánea: desde finales del siglo XIX a las Dictaduras. Madrid: Consejo Superior de Investigaciones Científicas, pp. 69-76.

Luebbert, Gregory M. (1997). Liberalismo, Fascismo o Socialdemocracia. Clases Sociales y orígenes políticos de los regímenes de la Europa de entreguerras. Zaragoza: Prensas Universitarias de Zaragoza.

Lyttelton, Adrian (1973). "El patronazgo de la Italia de Giolitti". Revista de Occidente, Tomo 43, N. 127, Out.-Dez., pp. 94-117.

Madeira, João (2013). História do Partido Comunista Português. Lisboa: Tinta da China.

Marques, A. H. de Oliveira (1980). A 1. $\underline{a}$ República Portuguesa (alguns aspectos estruturais). 3. a edição, Lisboa: Livros Horizonte.

Marques, A. H. de Oliveira (Coordenação de). (1991). Portugal da Monarquia para a República. Nova História de Portugal, Vol. 11, Lisboa: Editorial Presença.

Marques, H. de Oliveira (Coordenação de) (2000). Parlamentares e Ministros da 1. a República. Porto: Edições Afrontamento/Assembleia da República.

Matos, Luís Salgado de (2010). Tudo o que sempre quis saber sobre a Primeira República em 37 mil palavras. Lisboa: Imprensa de Ciências Sociais.

Mavrogordatos, George Th. (1983). StiIlborn Republic. Social Coalitions and Party Strategies in Greece, 1922-1936. Berkeley: University of California Press.

Meneses, Filipe Ribeiro de (1998). “Sidónio Pais, the Portuguese "New Republic» and the challenge to liberalism in southern Europe". European History Quarterly, Vol. 28, no. 1 (January), pp. 109-130.

Meneses, Filipe Ribeiro de (2004). "O impacto da Primeira Guerra Mundial no sistema político português". in Manuel Baiôa (Ed.), Elites e Poder. A Crise do Sistema Liberal em Portugal e Espanha (1918-1931). Lisboa: Edições Colibri/ClDEHUS.UE, pp. 421-446.

Meneses, Filipe Ribeiro de (2011). “Sidónio Pais e o Sidonismo". in Luciano Amaral (Org.), Outubro: A Revolução Republicana em Portugal (1910-1926). Lisboa: Edições 70, pp. 227-256.

Miranda, Jorge (1985). Manual de Direito Constitucional. 3. a ed., Tomo I. Coimbra: Coimbra Editora.

Moreno Luzon, Javier (1995). "Teoría del clientelismo y estudio de la política caciquil". Revista de Estudios Políticos, N.으 89, Julio-Septiembre, pp. 191-224.

Moreno Luzon, Javier (1999). “El clientelismo político: Historia de un concepto multidisciplinar". Revista de Estudios Políticos, N.o 105, Julio-Septiembre, pp. 73-95.

Moreno Luzón, Javier (2004). “El Partido Liberal español y la crisis de la Restauración (1917-1923)". in Manuel Baiôa (Ed.), Elites e Poder. A Crise do Sistema Liberal em Portugal e Espanha (19181931). Lisboa: Edições Colibri/CIDEHUS. UE, pp. 133-164.

Moreno Luzon, Javier (2006). “A historiografia sobre o caciquismo espanhol: balanço e novas perspectivas". Análise Social, N. 178, pp. 9-29.

Mouzelis, Nicos P. (1986). Politics in the Semi-Periphery. Early Parliamentarism and Late Industrialization in the Balkans and Latin America. London: Macmillan.

Noiret, Serge (1994). La nascita del sistema dei partiti nell'Italia contemporanea. La proporzionale del 1919. Roma: Piero Lacaita editore.

Noiret, Serge (1997 a). "La introducción del sufragio universal y de la representación proporcional en Italia en 19181919: una frágil modernización democrática". in Salvador Forner (Coor.), Democracia, elecciones y modernización en Europa, Siglos XIX y XX. Madrid: Cátedra, pp. 73-95.

Noiret, Serge (1997 b). "Le campagne Elettorali dell'Italia Liberale: dai Comitati al Partitti". in Pier Luigi Ballini (a cura di), Idee di Rapresentanza e Sistemi Eletto- rali in Italia tra Otto e Novecento. Venezia: Instituto Veneto di Scienze Lettere ed Arti, pp. 383-454.

Orsini, Fabio Grassi; Quagliariello, Gaetano (a cura di), (1996). Il partito político dalla Grande Guerra al Fascismo. Crisi della rapresentanza e riforma dello Stato nell'età dei sistemi politici di massa (1918-1925). Bologna: II Mulino.

Peña Guerrero, María Antonia (1998). Clientelismo político y poderes periféricos durante la Restauración. Huelva 1874-1923. Huelva: Universidad de Huelva.

Pereira, José Pacheco (1999). Álvaro Cunhal: Uma biografia política. Vol. I, Lisboa: Temas e Debates.

Pinto, António Costa (2000). “Portugal: Crises and early authoritarian takeover". in Dirk Berg-Schosser \& Jeremy Mitchell (Eds.), Conditions of democracy in Europe, 1919-1939. London: Macmillan Press, pp 354-380.

Pinto, António Costa (2001). Fascismo e Nazionalsindacalismo in Portogallo: $1914-$ 1945. Roma: Antonio Pellicani.

Pinto, António Costa (2004). "A queda da 1. a República Portuguesa: uma interpretação". in Manuel Baiôa (Ed.), Elites e Poder. A Crise do Sistema Liberal em Portugal e Espanha (1918-1931). Lisboa: Edições Colibri/CIDEHUS.UE, pp. 165-183.

Pinto, Ricardo Leite (1995). “União Liberal Republicana (ULR), 1926-1930. Um partido político na transição da I República para o Salazarismo". Polis, n. 4/5, Julho-Dezembro, pp. 131-260.

Pombeni, Paolo (1994). Partiti e Sistemi Politici nella Storia Contemporanea (18301968), Bologna: II Mulino.

Queirós, António José Sousa Monteiro de (2008). A Esquerda Democrática e o final da Primeira República. Lisboa: Livros Horizonte.

Ramos, Rui (2000). "O fim da República". Análise Social, № 153, pp. 1059-1082.

Ramos, Rui (2001). A Segunda Fundação (1890-1926). História de Portugal, Vol. VI, Lisboa: Editorial Estampa.

Ramos, Rui (2004). “Foi a Primeira República um regime liberal? Para uma caracterização política do regime republicano português entre 1910-1926". in Manuel Baiôa (Ed.), Elites e Poder. A Crise do Sistema Liberal em Portugal e Espanha (1918-1931). Lisboa: Edições Colibri/ClDEHUS.UE, pp. 185-246. 
Reis, António (2004). “O grupo Seara Nova: Uma resposta das elites intelectuais à crise do sistema liberal". in Manuel Baiôa (Ed.), Elites e Poder. A Crise do Sistema Liberal em Portugal e Espanha (1918-1931). Lisboa: Edições Colibri/ClDEHUS.UE, pp. 325-352.

Ridolfi, Maurizio (1992). II PSI e la nascita del partito di massa, 1892-1922. Roma: Laterza.

Ridolfi, Maurízio (1999). Interessi e Passioni. Storia dei partiti politici italiani tra I'Europa e il Mediterraneo. Milano: Bruno Mondadori.

Robles Egea, Antonio (Comp.). (1996). Política en penumbra. Patronazgo y clientelismo políticos en la España contemporánea. Madrid: Siglo Veintiuno Editores.

Rosas, Fernando. (2010). Porque venceu e porque se perdeu a I República. Lisboa: Bertrand Editora.

Samara, Maria Alice (2004). "O Sidonismo: regime de tipo novo?". in Manuel Baiôa (Ed.), Elites e Poder. A Crise do Sistema Liberal em Portugal e Espanha (19181931). Lisboa: Edições Colibri/CIDEHUS. UE, pp. 399-420.

Samara, Maria Alice (2002). Verdes e Vermelhos. Portugal e a Guerra no ano de Sidónio Pais. Lisboa: Editorial Notícias.
Santos, Miguel Dias dos (2003). Os Monárquicos e a República Nova. Coimbra: Quarteto.

Schwartzman, Kathleen C. (1989). The Social Origins of Democratic Collapse: The First Portuguese Republic in the Global Economy. Lawrence: Kansas.

Sierra, María (1996). La política del pacto. El sistema de la restauración a través del partido conservador sevillano (18741923). Sevilla: Diputación de Sevilla.

Silva, Armando B. Malheiro da (2006). Sidónio e Sidonismo. 2 Vols., Coimbra: Imprensa da Universidade de Coimbra.

Silva, João Manuel Garcia Salazar Gonçalves da (1996). O Partido Reconstituinte: Clientelismo, faccionalismo e a descredibilização dos partidos políticos durante a Primeira República (1920-1923). (Tese inédita de Mestrado). Instituto de Ciências Sociais da Universidade de Lisboa.

Silva, João Manuel Gonçalves da (1997). “O clientelismo partidário durante a I República: o caso do Partido Reconstituinte (1920-1923)". Análise Social, n.응 140, pp. 31-74.

Sousa, Marcelo Rebelo de (1983). Os Partidos Políticos no Direito Constitucional Português. Braga: Livraria Cruz.

Suárez Cortina, Manuel (1986). El Reformismo en España. Republicanos y Reformis- tas bajo la Monarquía de Alfonso XIII. Madrid: Siglo Veintiuno.

Tarchi, Marco (2000). "Italy: Early Crisis and Fascist Takeover". in Dirk Berg-Schlosser; Jeremy Mitchell, (Edited by), Conditions of Democracy in Europe, 1919-39. Systematic Case Studis. London: Macmillan Press, pp. 294-320.

Telo, António José (1977). O Sidonismo e o Movimento Operário Português. Lisboa: Ulmeiro.

Telo, António José (2000). "Sidónio Pais A Chegada do Século XX". in Nuno Severiano Teixeira; António Costa Pinto (Coordenadores), A Primeira República Portuguesa. Entre o Liberalismo e o Autoritarismo. Lisboa: Edições Colibri, pp. 11-24.

Valente, Vasco Pulido (1982). O Poder e o Povo. A Revolução de 1910. 2. a Edição, Lisboa: Moraes Editores.

Valente, Vasco Pulido (1997). A República VeIha (1910-1917). Ensaio. Lisboa: Gradiva.

Varela Ortega, José (1977). Los Amigos Políticos. Partidos, Elecciones y Caciquismo en la Restauración (1875-1900). Madrid: Alianza Universidad.

Varela Ortega, José (Director). (2001). El poder de la influencia. Geografía del caciquismo en España (1875-1923). Madrid: Marcial Pons. 